\title{
Synthesis, Characterization, and Hydrotreating Activity of NiW Presulfurized Catalysts Prepared via a Tetrathiotungstate-Intercalated NiAl LDH
}

\author{
Hao Wang*, Fan Yang, Zhendong Yang, Han Yang, Yan Wu \\ School of Chemistry and Chemical Engineering, Southwest Petroleum \\ University, Chengdu, Sichuan Province, 610500, China.
}




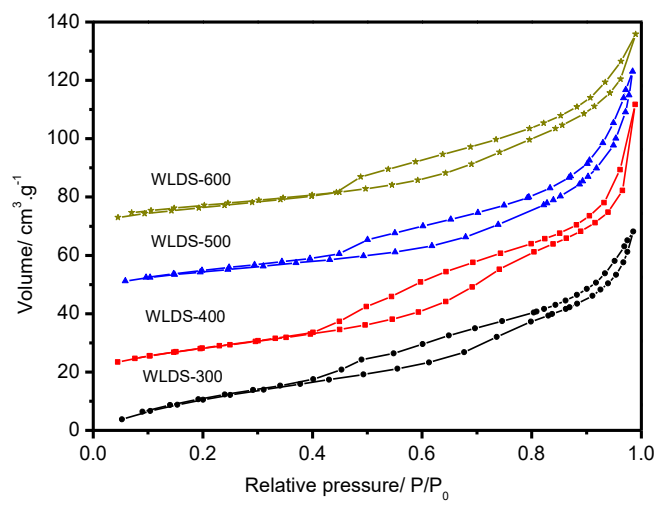

Figure S1. $\mathrm{N}_{2}$ adsorption-desorption isotherms of WLDS-300, WLDS-400, WLDS-500 and WLDS-600.

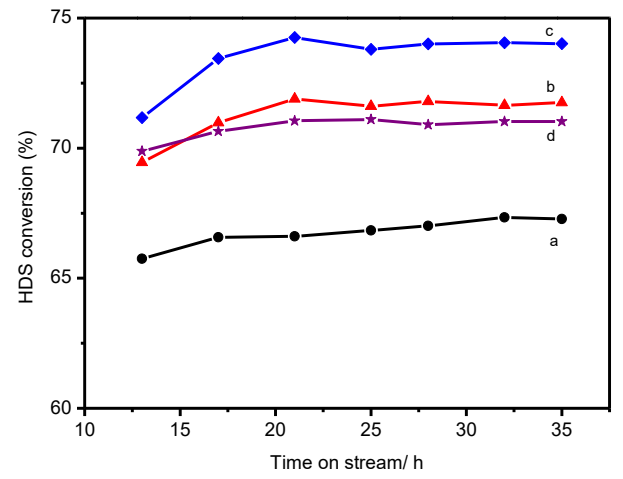

Figure S2. DBT HDS conversion with time on stream over presulfurized catalysts, (a) WLDS300, (b) WLDS-400, (c) WLDS-500 and (d) WLDS-600.

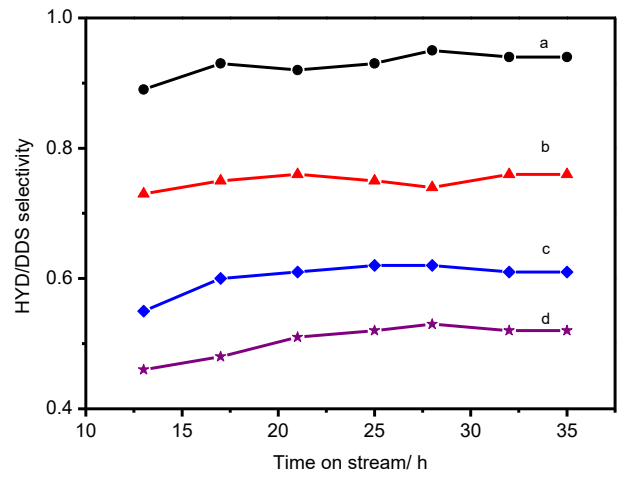

Figure S3. HYD selectivity of DBT with time on stream over presulfurized catalysts, (a) WLDS300, (b) WLDS-400, (c) WLDS-500 and (d) WLDS-600. 


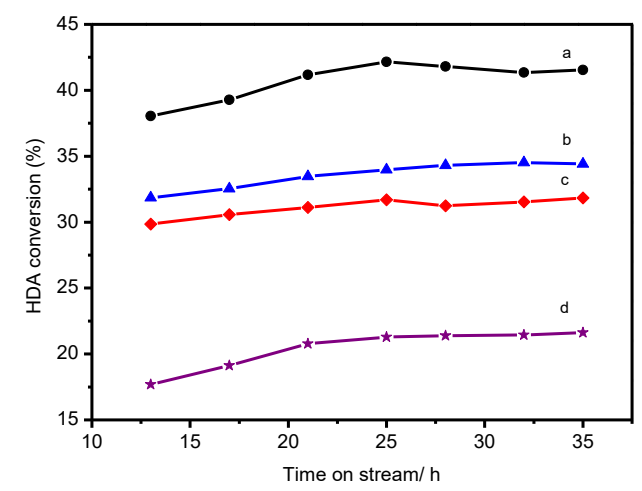

Figure S4. THN HDA conversion with time on stream over presulfurized catalysts, (a) WLDS300, (b) WLDS-400, (c) WLDS-500 and (d) WLDS-600.

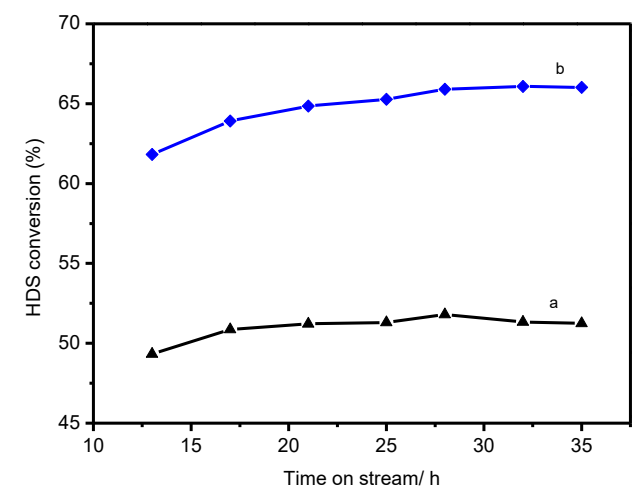

Figure S5. DBT HDS conversion with time on stream over reference catalysts, (a) LDO and (b) $\mathrm{NiWS} / \mathrm{Al}_{2} \mathrm{O}_{3}$.

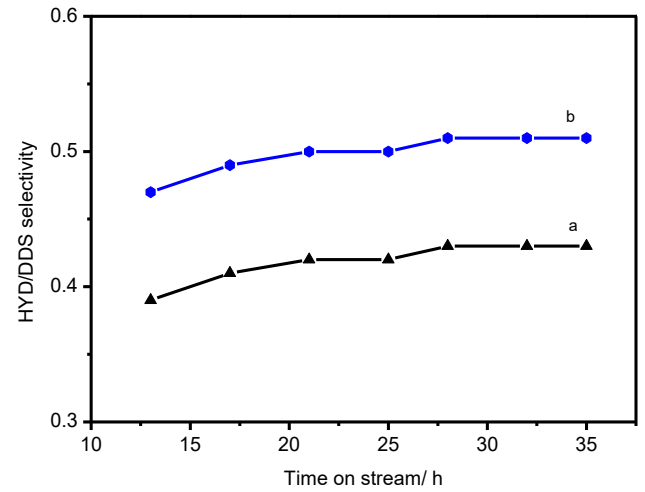

Figure S6. HYD selectivity of DBT with time on stream over reference catalysts, (a) LDO and (b) $\mathrm{NiWS} / \mathrm{Al}_{2} \mathrm{O}_{3}$. 


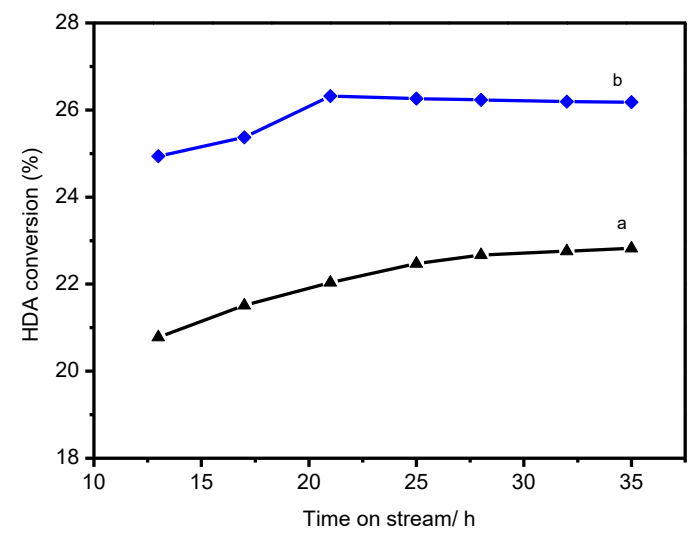

Figure S7. THN HDA conversion with time on stream over reference catalysts, (a) LDO and (b) $\mathrm{NiWS} / \mathrm{Al}_{2} \mathrm{O}_{3}$.

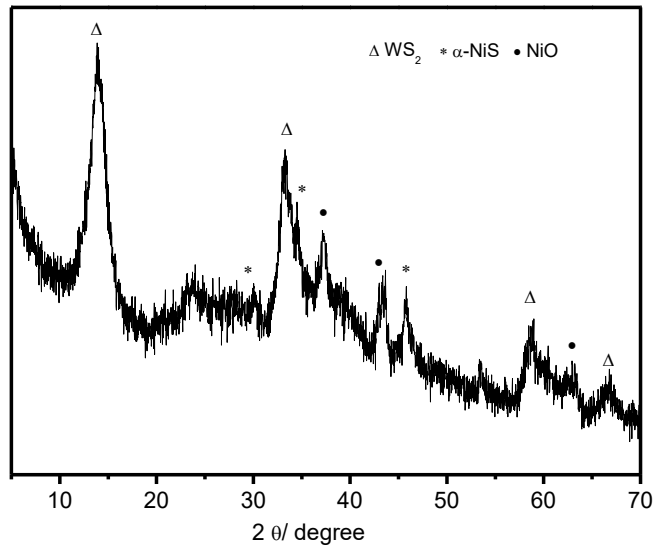

Figure S8. XRD pattern of $\mathrm{NiWS} / \mathrm{Al}_{2} \mathrm{O}_{3}$.

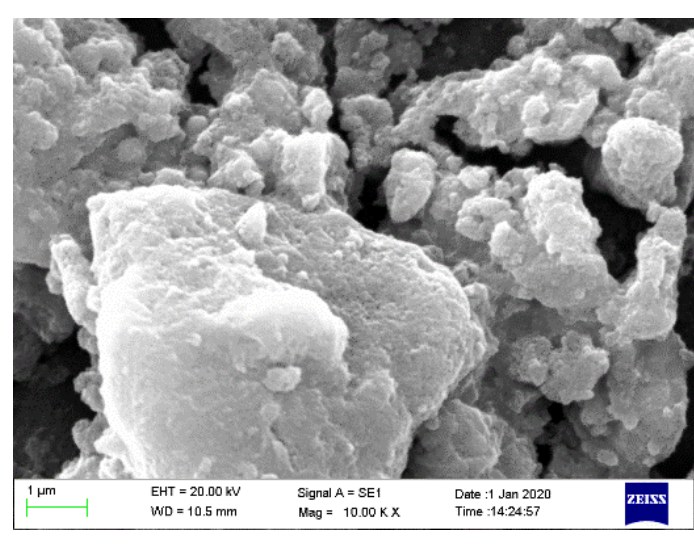

a

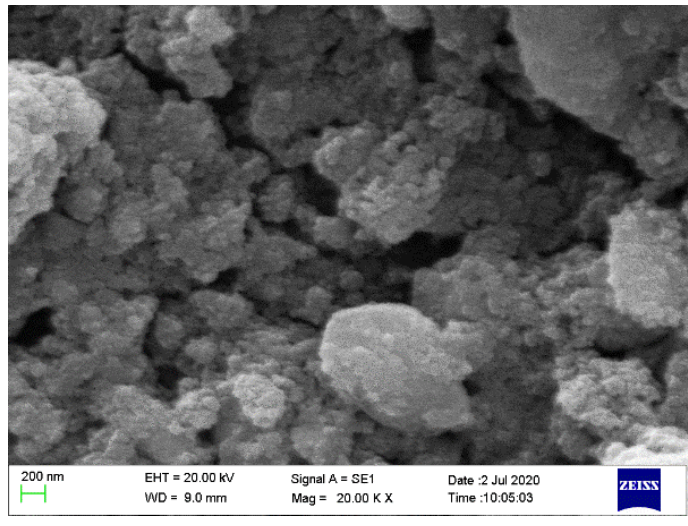

$b$

Figure S9. SEM micrographs of (a) NiAl-WS 4 LDH and (b) WLDS-300.

The representative SEM micrographs of NiAl-WS 4 LDH and WLDS-300 are shown in Figure $\mathrm{S} 9 . \mathrm{NiAl-WS} 4$ shows a plate-like morphology, which is typical for LDHs. ${ }^{1}$ 
After calcined at $300{ }^{\circ} \mathrm{C}$, layered structure is partial retained and more smaller platelets are observed, due to the cleavage of brucite-like layers. ${ }^{2}$

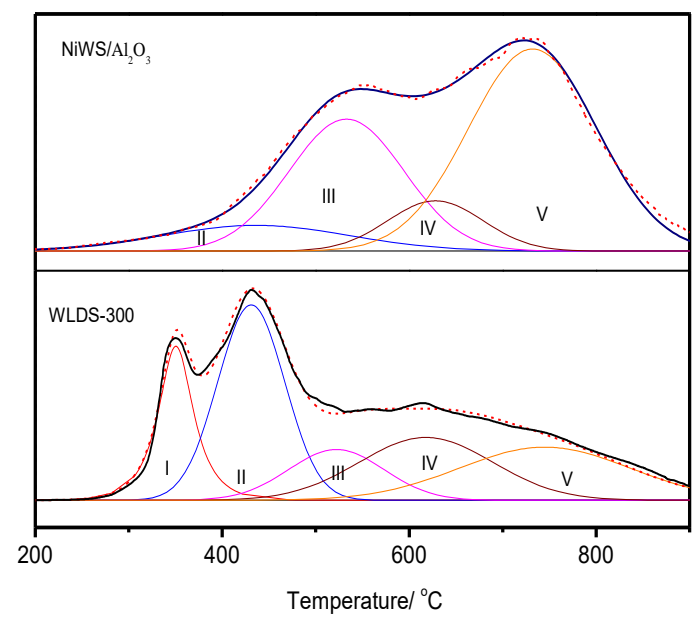

Figure S10. TPR-S profile of $\mathrm{NiWS} / \mathrm{Al}_{2} \mathrm{O}_{3}$ and WLDS-300.

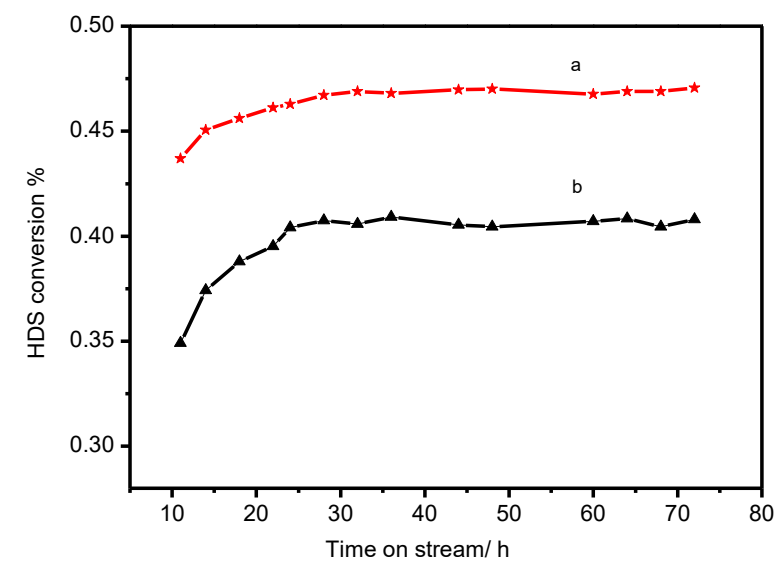

Figure S11. Diesel HDS conversion with time on stream over (a) WLDS-300 and (b) a commercial catalyst. 


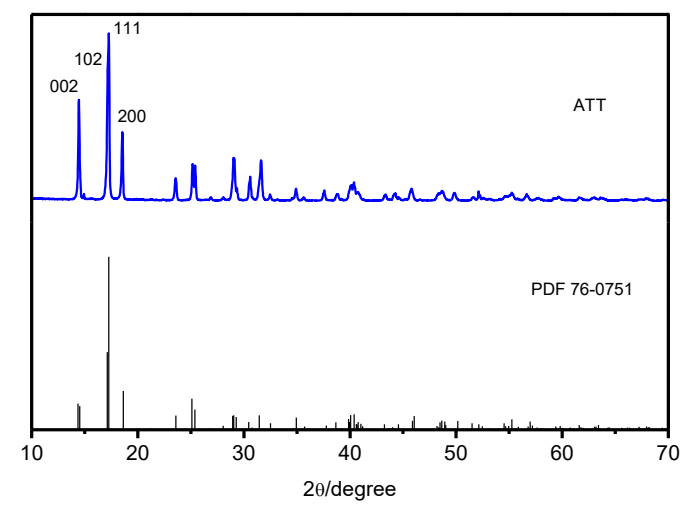

Figure S12. XRD pattern of as-synthesized ATT.

The XRD pattern of as-synthesized ATT (Figure S12) can be well indexed to orthorhombic ammonium tetrathiotungstate (ICDD PDF 76-0751). The sharp reflections at $14.4,17.1,17.3$, and $18.6^{\circ}$ are assigned to (002), (102), (111), and (200) crystal planes, respectively. No diffractions of impurities are observed. The CHNS elemental analysis and ICP-AES results show the mole ratio of $\mathrm{W}: \mathrm{N}$ : $\mathrm{S}$ is $1.00: 1.98$ : 4.03, which matches well with the stoichiometry of $\left(\mathrm{NH}_{4}\right)_{2} \mathrm{WS}_{4}$.

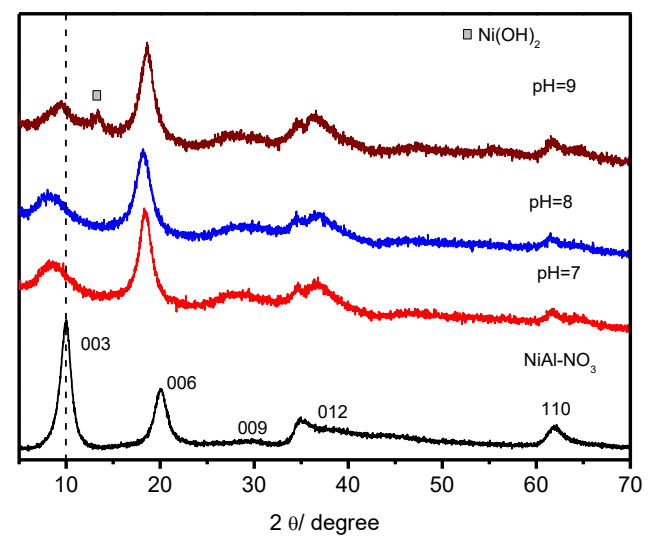

Figure S13. XRD patterns of NiAl-WS 4 synthesized under various initial $\mathrm{pH}$ values and NiAl-

$$
\mathrm{NO}_{3} \text { precursor. }
$$

At initial exchange $\mathrm{pH}$ of 7, 8, and 9, the (003) reflections of NiAl-WS 4 (Figure S13) are respectively present at $8.7,8.5$, and $9.3^{\circ}$, and the corresponding $d_{003}$ values are 1.02 , 
1.04 , and $0.95 \mathrm{~nm}$, respectively. For $\mathrm{NiAl}-\mathrm{NO}_{3}$ precursor, the $(003)$ reflection is present at $10.0^{\circ}$ and the $d_{003}$ value is $0.89 \mathrm{~nm}$. The enlarged $d_{003}$ suggests the intercalation of bigger $\mathrm{WS}_{4}{ }^{2-}$ in the interlayer. However, a reflection at $13.3^{\circ}$ assigned to $\mathrm{Ni}(\mathrm{OH})_{2}$ (ICDD PDF 73-2408) is observed in the sample synthesized at $\mathrm{pH}$ of 9. Moreover, the $d_{003}$ value reaches the maximum at $\mathrm{pH}$ of 8 , indicating the better intercalation. The acidification of tetrathiomolybdate or tetrathiotungstate solutions usually leads to the formation of molybdenum or tungsten sulfide precipitates. ${ }^{3,4}$ Therefore, the initial exchange $\mathrm{pH}$ is chosen at 8 .

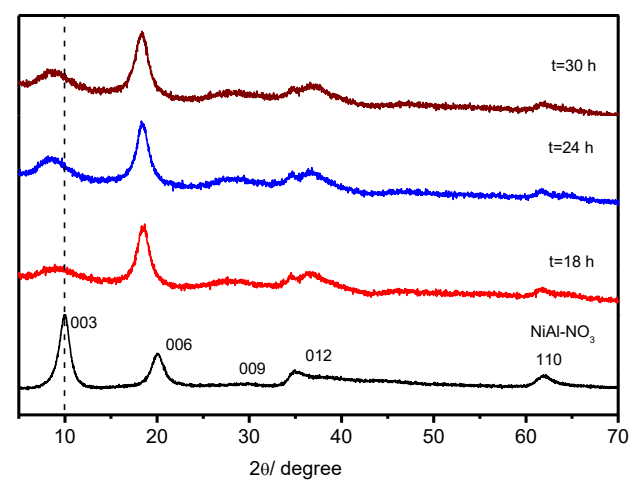

Figure S14. XRD patterns of NiAl-WS 4 synthesized at various exchange time and $\mathrm{NiAl}-\mathrm{NO}_{3}$ precursor.

As the exchange time increases, both the intensity of (003) reflection and the $d_{003}$ value increase up to $24 \mathrm{~h}$ and then remain nearly constant with further prolonged exchange time of $30 \mathrm{~h}$ (Figure S14). This suggests that the best crystallinity can be achieved with the exchange time of $24 \mathrm{~h}$. 


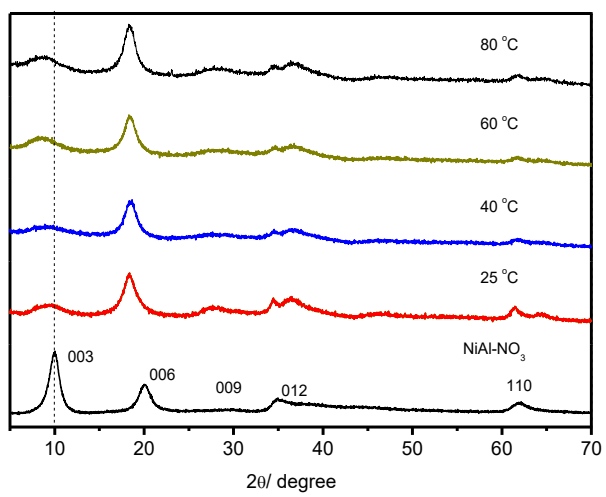

Figure S15. XRD patterns of NiAl-WS 4 synthesized at various exchange temperatures and

$\mathrm{NiAl}-\mathrm{NO}_{3}$ precursor.

The samples synthesized below $60{ }^{\circ} \mathrm{C}$ exhibit the relatively weak (003) reflections and small $d_{003}$ values. At 60 and $80{ }^{\circ} \mathrm{C}$, two samples show similar XRD patterns (Figure S15). Moreover, FT-IR spectra (Figure S16) show that the band at $1384 \mathrm{~cm}^{-1}$ assigned to $v 3$ stretching of $\mathrm{NO}_{3}{ }^{-}$vanishes when the temperature is raised above $40{ }^{\circ} \mathrm{C}$. The results imply that the full replacement of $\mathrm{NO}_{3}{ }^{-}$by $\mathrm{WS}_{4}{ }^{2-}$ and the ordered layer structure can be achieved at the exchange temperature of $60{ }^{\circ} \mathrm{C}$.

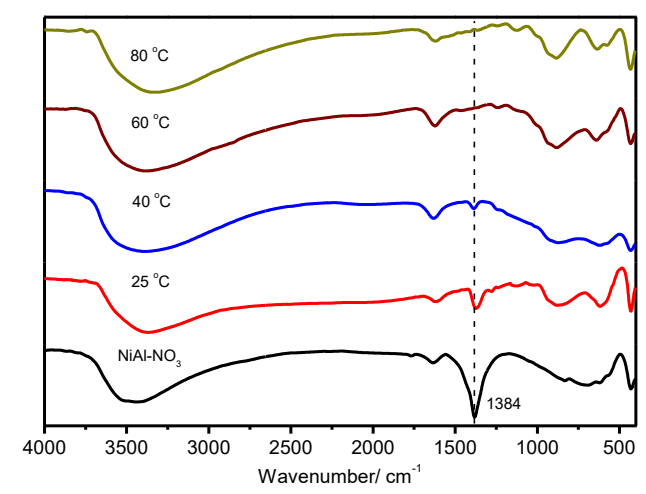

Figure S16. FT-IR spectra of NiAl-WS 4 synthesized at various exchange temperatures and $\mathrm{NiAl}-\mathrm{NO}_{3}$ precursor. 


\section{Reference}

(1) Wang, H.; Yang, Z.; Zhan, X.; Wu, Y.; Li, M. NiAlZrW hydrodesulfurization catalysts derived from tungstate intercalated NiAlZr layered double hydroxides. Fuel Process. Technol. 2017, $160,178-184$.

(2) Chen, Y.; Wang, L.; Zhang, Y.; Liu, T.; Liu, X.; Jiang, Z.; Li, C. A new multi-metallic bulk catalyst with high hydrodesulfurization activity of 4,6-DMDBT prepared using layered hydroxide salts as structural templates. Appl. Catal., A. 2014, 474: 69-77.

(3) Wang, H. W.; Skeldon, P.; Thompson, G. E. XPS studies of $\mathrm{MoS}_{2}$ formation from ammonium tetrathiomolybdate solutions. Surf. Coat. Technol. 1997, 91, 200-207.

(4) Voorhoeve, R. J. H.; Wolters, H. B. M. Tungsten sulfides obtained by decomposition of ammonium tetrathiotungstate. Z. Anorg. Allg. Chem. 1970, 370, 165-179. 